\title{
Toward a theory-led meta-framework for implementing health system resilience analysis studies: a systematic review and critical interpretive synthesis
}

Zeynab Foroughi ${ }^{1}$, Parvin Ebrahimi ${ }^{*}$, Aidin Aryankhesal' ${ }^{1}$, Mohammadreza Maleki ${ }^{1}$ and Shahram Yazdani ${ }^{2}$

\begin{abstract}
Introduction: The variety of frameworks and models to describe resilience in the health system has led researchers and policymakers to confusion and the inability to its operationalization. Therefore, the purpose of this study was to create a meta-framework using the Critical Interpretive Synthesis method.
\end{abstract}

Method: For this purpose, studies that provide theories, models, or frameworks for organizational or health system resilience in humanitarian or organizational crises were systematically reviewed. The search strategy was conducted in PubMed, Web of Science, Embase, and Scopus databases. MMAT quality appraisal tool was applied. Data were analysed using MAXQDA 10 and the Meta-ethnography method.

Results: After screening based on eligibility criteria, 43 studies were reviewed. Data analysis led to the identification of five main themes which constitute different framework dimensions. Health system resilience phases, attributes, tools, and strategies besides health system building blocks and goals are various dimensions that provide a systematic framework for health system resilience analysis.

Discussion: This study provides a systemic, comprehensive framework for health system resilience analysis. This meta-framework makes it possible to detect the completeness of resilience phases. It examines the system's resilience by its achievements in intermediate objectives (resilience system attributes) and health system goals. Finally, it provides policy solutions to achieve health system resilience using tools in the form of absorptive, adaptive, and transformative strategies.

Keywords: Health system, Resilience, Meta-framework, Critical interpretive synthesis

\section{Introduction}

Health system resilience is known as a way to achieve universal health coverage (UHC) through health system strengthening against chronic challenges and acute shocks [1]. Although the term "resilience" has

*Correspondence: ebrahimi.p@iums.ac.ir

${ }^{1}$ School of Health Management and Information Sciences, Iran University of Medical Sciences, Tehran, Iran

Full list of author information is available at the end of the article been employed in engineering, psychology, and ecology sciences for more than a decade, it has been used in health system research in recent years [2]. The negative consequences of the Ebola virus outbreak on the health system in West Africa, including interruption in the delivery of essential health services and losses of many lives, contributed to the popularity of the health systems resilience concept $[3,4]$. In the same way, the COVID-19 pandemic has increasingly raised the clarity of the need for resilience in health systems [5]. By 
definition, health system resilience is the ability of the system to prepare for and respond to sudden shocks and everyday challenges and its capacity to absorb deteriorations, adapt, and transform the health system to cope with them $[5,6]$.

The results of a concept analysis suggested that there is fragility in applying the health system resilience concept. Different researchers use various frameworks for analysing health system resilience [2]. Hence, there is no specific suggestion about achieving a resilient health system [7]. For example, Hollnagel focused on the concept of resilience engineering and defined four resilient health system capabilities as anticipating, monitoring, responding, and learning [8]. Kruk et al. also introduced the attributes of health system resilience, considering it as living organisms, including aware, diverse, self-regulating, integrated, and adaptive [9]. Blanchet et al. presented health system resilience capacities, including absorptive, adaptive, and transformative capacities [10].

The lack of a unified framework for studying health system resilience can hinder its operationalization [11]. Therefore, integration and unification of the current health system resilience frameworks are necessary for realizing its potentials [12]. Hence, we conducted this study to achieve a comprehensive framework for analysing health system resilience. This study applied reviewing and synthesis of the existing conceptual frameworks and finding the common elements among them. The initial study question was about detecting different components of a resilient health system that should be considered during resilience system analysis studies.

\section{Materials and methods}

This systematic review was conducted and is reported according to the Preferred Reporting Items for Systematic Reviews and Meta-Analyses (PRISMA) guidelines (Supplementary File 1).

\section{Eligibility criteria}

The inclusion criteria were all studies published in English with any quantitative or qualitative design and book chapters. Included studies should be introduced or defined a resilience theory, model, or framework in organizational or health system context and/or in connection with a humanitarian or organizational crisis. Also, reports published by international organizations were included. Studies related to ecological, or psychological resilience were excluded. Further, empirical studies that did not mention resilience system components were excluded.

\section{Information sources \& search strategy}

We applied the search strategy in PubMed, Web of Science, Embase, and Scopus databases in November 2020. Keywords include Resilience, resilient combining with organiz"/organis" or system or "health system" and theory, framework, model, and synonyms. Also, reference checking of detected studies and hand searching of related journals were conducted. The complete search strategies for all databases are presented in Table 1.

\section{Selection process}

Duplicate documents were removed using Endnote software. Tow authors (ZF and AA) screened retrieved studies. In the first stage, screening was regarding the relevance of the title and abstract. Next, the studies' full-texts were screened in terms of compliance with the inclusion and exclusion criteria. The authors discussed controversies in the screening process.

\section{Quality appraisal}

Quality assessment was based on Mixed Methods Appraisal Tool (MMAT), VERSION2018. This tool is applicable for quality assessment of systematic mixed studies review that needs to quality assessment of various quantitative, qualitative, and mixed-method studies [13]. This tool rates studies with a five-point scale:

Table 1 The search strategies for all databases and their results

\begin{tabular}{|c|c|c|}
\hline Database & Search Strategy & $\begin{array}{l}\text { Document } \\
\text { Results }\end{array}$ \\
\hline WOS & $\begin{array}{l}\text { TITLE: (Resilience OR resilient) AND TITLE: (System OR model OR framework OR theory OR organiz* OR organis* OR concept) } \\
\text { AND TOPIC: (healthcare OR "health care" OR "health system" OR "health sector") } \\
\text { Timespan: All years. Indexes: SCI-EXPANDED, SSCI, A\&HCI, CPCI-S, CPCI-SSH, BKCI-S, BKCI-SSH, ESCI }\end{array}$ & 230 \\
\hline PubMed & $\begin{array}{l}\text { (Resilience[Title] OR resilient[Title]) AND (System[Title] OR model[Title] OR framework[Title] OR theory[Title] OR } \\
\text { organization[Title] OR organizational[Title] OR concept[Title]) }\end{array}$ & 701 \\
\hline Embase & $\begin{array}{l}\text { (resilient:ti OR resilience:ti) AND (framework:ab,ti OR model:ab,ti OR program:ab,ti OR indicator:ab,ti OR index:ab,ti) AND } \\
\text { (system:ab,ti OR organization:ab,ti OR organizational:ab,ti OR theory:ab,ti) }\end{array}$ & 834 \\
\hline Scopus & $\begin{array}{l}\text { (TITLE (resilience OR resilient) AND TITLE (system OR model OR framework OR theory OR organiz* OR organis* OR concept OR } \\
\text { program OR indicator) AND TITLE (healthcare OR "health care" OR "health system" OR "health sector")) }\end{array}$ & 181 \\
\hline
\end{tabular}


$0,25,50,75$, and 100 (where 100 indicates the highest level of quality). Moreover, non-empirical studies that did not have an explicit research question based on the definition of this checklist and did not respond to the collected data were excluded from the appraisal process. Two researchers conducted the ratings. Disagreements were resolved using discussion and a third researcher. Given that the present systematic review was qualitative, no study was excluded for having a low rating. The results of study ratings are applied in the interpretation of data.

\section{Data collection and analysis}

This study used the critical interpretive synthesis, as an empirical method with the aim of theorization. The method is specified for analyzing studies with diverse qualitative and quantitative methods [14]. The motivations for using this method were its qualitative principles [15], capability to analyze and interpret complex literature [16], and its ability to develop a new concept, framework, or model that is the aim of the present study [15, 17]. Critical interpretive synthesis deploys meta-ethnography strategies [18]. While the traditional reviews focus on aggregative synthesis, the focus of critical interpretive synthesis is on the interpretive synthesis [19]. Data analysis was based on the meta-ethnography method using MAXQDA 10 software. Applying this method in the first step, the key themes in each study were identified, then the authors translated the themes from various studies into each other. In the second step, controversies among models were detected and explained. Finally, a general and comprehensive interpretation was developed.

\section{Results}

The search strategy contributed to the identification of 1567 studies. After the two-stage screening, 43 studies met eligibility criteria. The PRISMA flow diagram of detected studies was presented in Fig. 1.

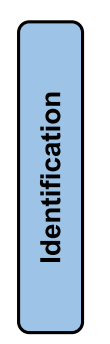

Records identified from:

PubMed $(\mathrm{n}=701)$

Web of Knowledge $(n=230)$

Embase $(\mathrm{n}=834)$

Scopus $(\mathrm{n}=181)$

Google for gray literature $(\mathrm{n}=2)$

Hand searching \& reference

cheking $(n=4)$
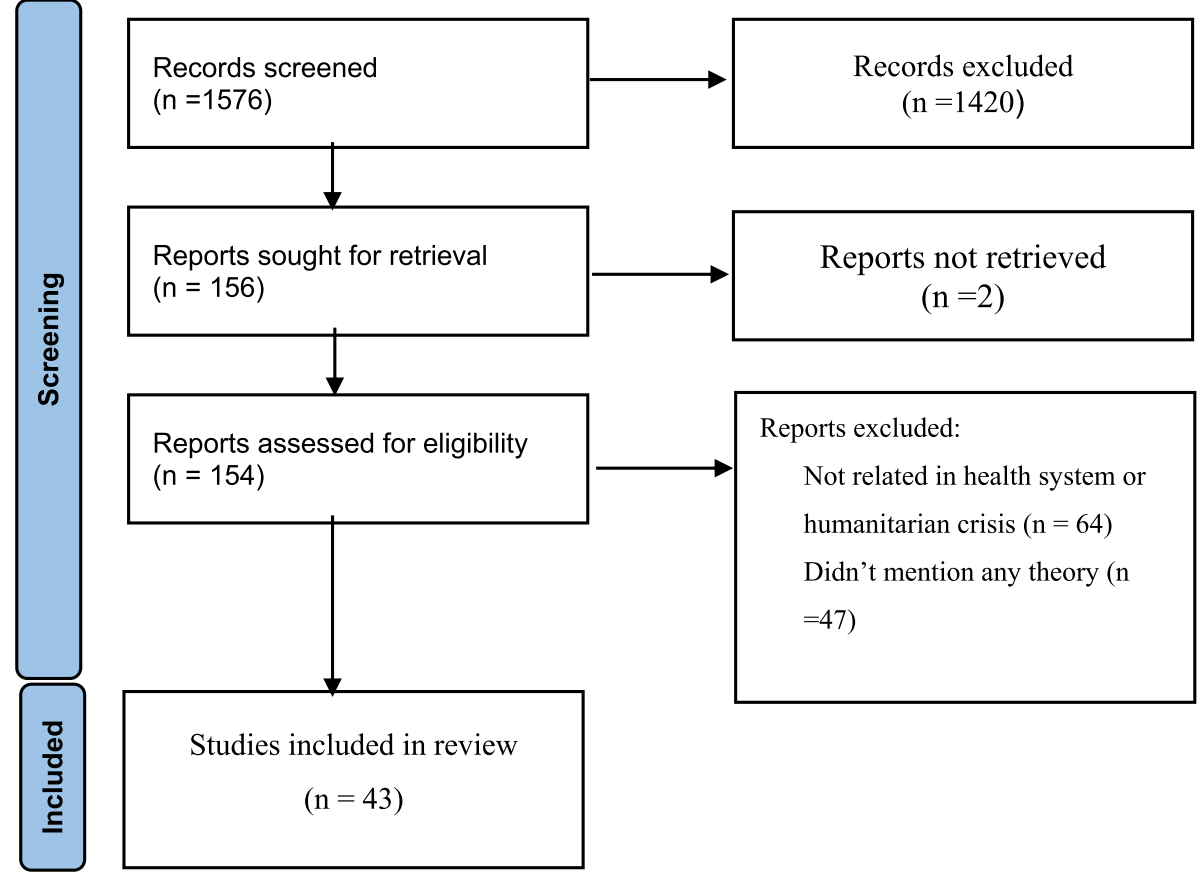

Studies included in review

$(n=43)$

Fig. 1 PRISMA 2020 follow diagram 


\section{Quality appraisal}

Since the present study sought to identify existing theories, a large number of detected studies (35\%) were nonempirical. Almost $53 \%$ of studies gained a high-quality score (100 or 75$)$. Only $11 \%$ of studies were in low rating.

\section{Synthetic model}

Review and critical interpretive analysis of studies indicated five main themes. These themes constitute the health system resilience analysis meta-framework. Accordingly, our synthetic model consists of health system resilience phases, attributes, main strategies, tools, and relationships with health system building blocks. Detected themes and related studies are presented in Table 2.

\section{Health system resilience phases}

The included studies referred to five main interrelated phases in system resilience.

\section{Phase I: anticipation}

Anticipation is the first phase of any activity to achieve health system resilience [7, 30, 39, 53, 55, 57-59]. Health systems need to acknowledge their vulnerabilities before providing any response $[48,60]$. In this phase, risk analysis and risk assessment methods will be applied [41]. This concept is referred to as forecasting, foresight, predicting, or detection of adverse events [30], potential system vulnerabilities [30,61], uncertainties [10], deteriorations [53], or possible scenarios using various tools such as simulation methods [61]. This phase requires a powerful information system as well as good collaboration and coordination [41].

\section{Phase II: preparation}

In the preparation phase, based on the type of risk and system vulnerabilities identified, the essential capacities of the health system will be promoted $[5,6,53]$. During this phase, planning [32], different response plans [5], scenario exercises, leadership and command structure in emergencies, legal preparations, and control and monitoring structures are defined [54].

\section{Phase III: response}

Responding is defined as the appropriate reaction to changing circumstances and is essential to guarantee good performance $[2,7,10,30,32,46,61,62]$. It requires the proper anticipation and preparations [45]. This phase should include all health system building blocks (Leadership \& governance, service delivery, human resources, financing, drug \& medical equipment, and information system) [10]. Moreover, the quality and the rapidity of decisions depend on suitable collaboration and coordination $[10,25]$.

\section{Phase IV: recovery}

The majority of studies referred to recovery as the last phase to achieve system resilience [30, 33, 39, 49, 54, 58]. Indeed, resilient systems have plans to return to stable states [30]. Self-regulation, another expression of this phase, refers system's ability to reduce performance deteriorations and absorb environmental changes [28, 47, $52,59]$. Recovery level and recovery time are two evaluation indicators of this phase [61]. The activities of this phase have a long-term view and require policymaking, analysis, and evaluation skills to detect optimal applied response plans. The recovery phase improves system preparedness through reactive and proactive activities to adapt old structures or create new ones $[57,63]$.

\section{Phase VI: growth}

Some studies considered growth as the last phase of the creation of resilient systems [59]. In other words, system capabilities will improve during the challenging condition through learning tools and growth that occurs in the long term [57, 59, 64].

\section{Health system resilience attributes Awareness}

A resilient system with a good understanding of its existing situation, including the operational environment, needs, and resources, can well predict future internal and external changes as well as timely informing decisionmakers and the public about crisis and its potential implications on the system [10, 20, 23, 31, 48, 65]. Kruk et al. named this attribute "cognitive capacity" and defined it as the ability of the system to detect and interpret shocks and chronic challenges (sense-making) [32]. Also, Blanchet et al. considered system "knowledge" and defined it as the capacity of collecting, analysing, and interpreting the information in addition to awareness [10]. Situation awareness requires appropriate collaboration and coordination between different stakeholders in the system [41]. Besides, a powerful information system with the ability to early detection, analyzing, and share information, including weak change signals from various internal and external parts of the health system, is a necessity for an aware health system, as a complex adaptive system [41, 52, 61]. In brief, awareness is composed of three main components of predicting, monitoring, and communicating, leading to sensemaking (ability to detect and interpret system changes) [28, 37, 47, 58, 59].

\section{Surge capacity}

The ability to increase the capacity of various system components (Health system six building blocks) in response to shocks or everyday challenges defines surge capacity $[20,25,27,54]$. Barasa et al. specified this 


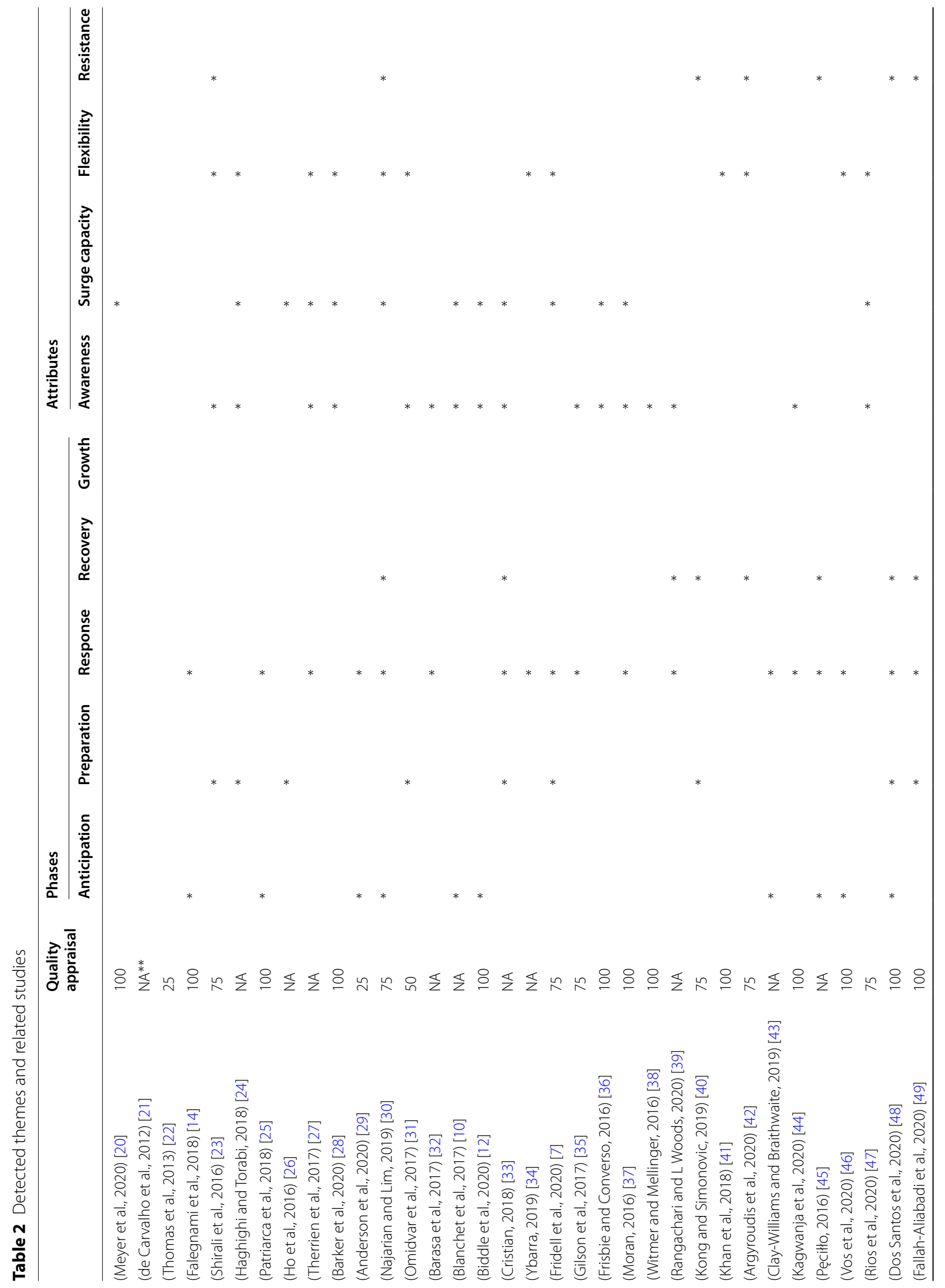




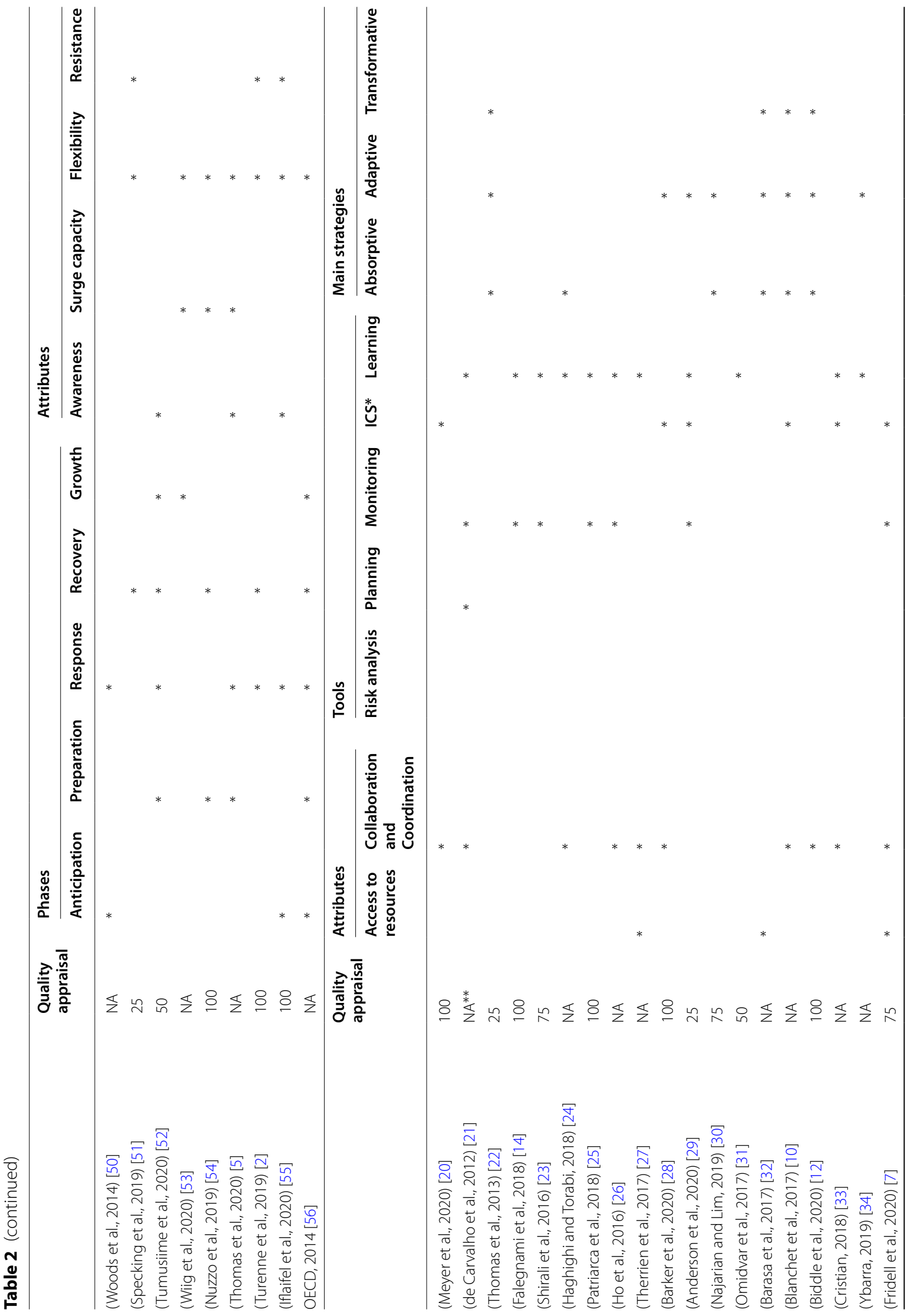




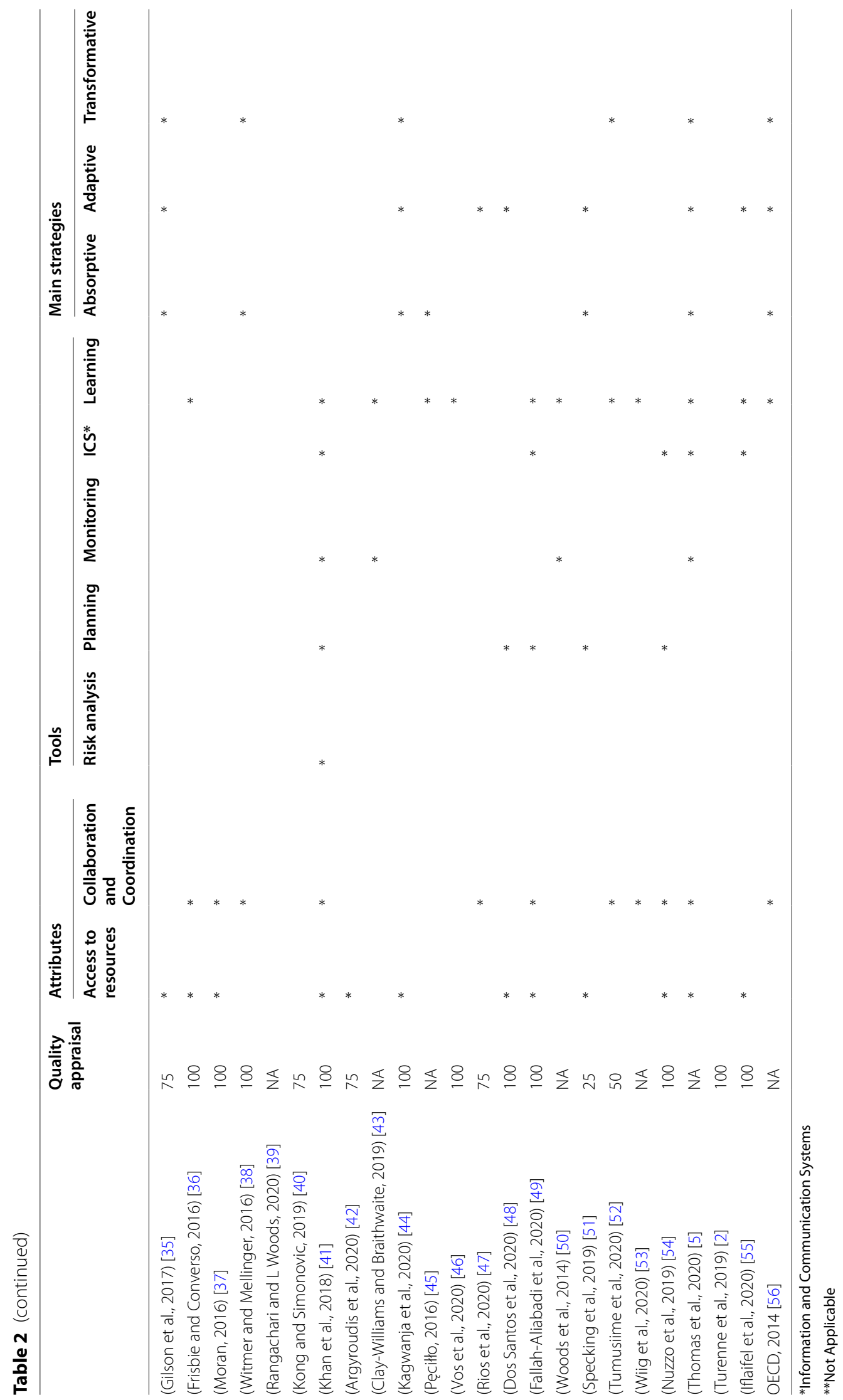


attribute as "behavioural capacity" which is the system's ability to respond to unforeseen circumstances based on learnings and preparations [44]. Also, some studies mentioned the term "agility" and the ability to change in an uncertain environment $[61,64,65]$. Hence, a resilient system will adapt the capacities of the health system building blocks upon understanding weak signals through its learning tools and awareness attribute [20, 27]. Learning tools assist the system in predicting appropriate and adequate capacity in different situations [44].

\section{Flexibility}

A resilient health system has flexible managerial and executive structures and coping strategies which can be adjusted in an emergency [23, 28, 47, 54, 66]. In another definition, flexibility refers to the extent and rapidity of system adaptations to shocks without failure in system processes [61]. In this regard, studies referred to "Redundancy" which is the existence of various executive solutions, choices, and adaptive options under pressure conditions [42, 58, 65]. Also, redundancy is about continuity of services due to the presence of various staff and equipment that can perform specific tasks [61]. In addition, some researchers mentioned the "Diversity" of health system building blocks in different situations $[28,47,52,58]$. Flexibility relates to the anticipation of uncertainties and is dependent on the learning tool and transformative strategies [67, 68]. Provision of safety inventory, multiple sources of supplies, and multipurpose equipment and staff are some examples of flexibility [68].

\section{Resistance}

This attribute is also known as "Robustness", "stability", or "coping" is about the system withstanding challenges and deteriorations $[30,42,49,61,65,66]$. This attribute results from the recovery phase and means the ability to maintain the main system characteristics and continuity of its critical operations [59].

\section{Access to resources}

Resource availability or resourcefulness, including human and financial resources, materials, and technologies specified to face a crisis, is an empowering factor to achieve system resilience [42, 66]. The resilience system can mobilize, acquire and distribute essential resources and assets against the crisis. Also, it has appropriate resource allocation strategies that ensure timely access to resources [37, 48, 49, 61].

\section{Collaboration and coordination}

Several studies referred to collaboration and coordination as an important resilient system attribute [2, 10 , 33, 41, 48]. Collaboration and coordination are among the properties of an integrated system against crisis and emergencies [41, 52, 65, 68]. Health system resiliency is not possible without a proper understanding of the role of its actors and stakeholders $[28,53]$. Resiliency requires predetermined coordination mechanisms in which power dynamics are considered [2, 20, 49]. Collaboration and coordination influence preparation, response, and recovery phases and contribute to flexibility through the creation of a shared understanding of the situation $[41,67,68]$. It also will be influenced by information and communication system [20]. Blanchet et al. called this attribute "capacity to manage interdependency" which means managing stakeholders' cross skills and feedbacks [10].

"Community engagement" constitutes a necessary aspect of collaboration and coordination in most resilience system theories and models [28, 33, 41, 54]. Community engagement and community involvement in decision makings can lead to cultural consideration in the implementation of policies and programs, creating a shared understanding with community and trust $[28$, $41,54]$.

\section{Health system resilience tools Risk analysis}

Detecting system vulnerabilities and planning for preparation and mitigation of adverse effects requires risk analysis tools and measuring the magnitude and severity of risks [63]. Therefore, risk analysis is the first step toward awareness and requires good collaboration and coordination and promoting information and communication systems to anticipate them $[41,49]$.

\section{Planning}

The resilient health system should have plans to solve the aftermath problems of the crisis [48, 54, 63]. Adaptable responses and resource allocation plans are necessary to cope with rapidly changing circumstances and become a resilient health system [54]. A resilient system requires preparedness, responses, and recovery plans, including contingency plans and emergency regulations [49]. Planning clarifies roles and responsibilities and facilitates understanding of system structure and functions. An appropriate plan will lead to creating collaborative networks [41].

\section{Monitoring}

Monitoring of the outcomes health system and intermediate activities is an essential tool to reach health system resilience $[14,45,50]$. Monitoring uncontrolled or unwanted consequences of small changes is a necessity for anticipation [58, 61]. Also, early detection of any change signals through leading and lagging indicators 
will improve awareness and lead to an effective response $[25,62]$.

\section{Information and communication systems}

Information and communication systems are also vital tools for a resilient health system [20, 27, 28, 41, 49, 54]. The resilient health system provides communication links between network members and supports information and communication system infrastructures [54, 59] Also, risk communication protocols and feedback loops are two main functions of information and communication systems [10]. This tool will facilitate awareness, improve learning, collaboration and coordination, response, and preparedness against chronic challenges and shocks [7].

The effectiveness of information and communication systems depends on the availability of required data, quality of data, and essential infrastructures to transfer on-time information $[7,52]$. Also, owning multiple information sources (Source resilience) will improve the reliability of information and communication systems [36, 37].

\section{Learning}

Learning from positive and negative experiences, success or failures, in extreme events or day-to-day activities, has a pivotal role in resiliency $[14,25,27,45,50,58,59$, $62,65,66]$. Indeed, a resilient health system focuses on how to learn from events [52]. Effective learning provides appropriate analytical indicators to assist anticipation and monitoring [25]. In addition, learning will improve system responses and requires evaluation and feedback mechanisms [41]. Developing individuals and the entire system knowledge and skills to deal with the adverse condition through learning mechanisms, including training programs, practice, and experience, will lead to system resilience improvement $[20,33,49,66]$.

\section{Institutionalization}

Several researchers specified the importance of capacity building and providing necessary institutional software and hardware to respond, cope with and adapt to crisis conditions [48]. For example, Blanch et al. argued that a resilient system could create organizations that are socially accepted and contextually compatible and called it "legitimacy" which can be achieved through community engagement [10]. Also, Albanese et al. introduced institutional capacity building as one of the necessary infrastructures for building a resilient hospital and achieving minimum standards $[33,69]$.

\section{Health system resilience main strategies Absorptive strategies}

Absorptive strategies, also known as persistence or situated resilience strategies, protect the system against shocks and the impact of hazards, which are usually small-scale shocks or events [32, 62, 70]. These strategies return the system to its original state or reduce the severity and implications of the crisis on the system without making any particular change in structure, using available resources and capacities (skills, knowledge, tools, and data) $[10,30,32,44,62,70]$. Such strategies are generally used in the response phase [62].

\section{Adaptive strategies}

Adaptive strategies, named structural resilience, can lead to a limited number of gradual adjustments in the structure or process of the system $[32,44,62,70]$. These strategies promote service delivery at the same level before the crisis and maintain core system activities using less or different resources [10]. Adaptive strategies will apply for more intensive challenges which absorptive strategies can't deal with [32].

\section{Transformative strategies}

Transformative strategies or systemic resilience create long-term and significant changes in the system structure and functions in response to massive environmental changes or challenges $[10,32,44,52,62,70]$.

\section{WHO health system six building blocks Leadership and governance}

Leadership can cause influence and be affected by resilient system attributes, strategies, and tools simultaneously. A resilient health system creates a transparent and flexible crisis leadership and governance structure $[54,71]$. It chooses the leadership style according to the context [71]. The leadership and governance affect coordination and collaboration by identifying and employing various actors (for example between the private and public sectors in the health system). Also, it makes capacity for anticipation, planning, and institutionalization possible $[41,48]$. The leadership and governance should focus on transparency, responsiveness, equity, and control and monitoring of other system components (service delivery, financing, human resources, etc) [41, 71].

\section{Human resources}

To achieve health system resiliency, we need a resilient workforce as well $[41,45]$. The resilient health system workforce has flexibility, including redundancy, adequate health workforce, additional workforce, and health workforce with multiple skills [7, 41, 54]. In addition, they receive the necessary training to deal with various crises (learning tools), for example, communication and collaboration, as the basic skills to deal with the crisis [20, $49,54]$. 


\section{Financing}

Crisis financial management [49], sufficient financial capacity to deal with the crisis [20,48], using diverse and sustainable financial resources (flexibility) [54], timely access to financial resources [54], effective allocation, and using current resources [7], and planning to distribute resources during the crisis [20], are essential tips for creating a resilient health system.

\section{Information system}

The possibility of timely knowledge and information exchange and the existence of quality monitoring systems will lead to improved policymaking and resiliency of the health system through improving preparedness, response, and accelerating adaptation to various shocks and chronic challenges [7, 33, 52]. A resilient health system has "source resiliency" which is the existence of multiple information sources that can improve policymakers' understanding of the system status in the time of crisis [36, 37]. The information system is a prerequisite for monitoring and learning through all levels (including the workforce, patients, families, and healthcare providers) [62].

Also, preservation, maintenance, and safety assurance of information and communication systems are necessary for resiliency in the health system [49]. A robust information system will improve collaboration and coordination, such as creating client-based information systems that can improve the relationships between the health system and its client [10]. In summary, the resiliency of the health system depends on the resiliency of its networking capacity to receive accurate and timely information [27].

\section{Service delivery}

Reducing services or patient discharges are usually the first reactions of health systems against the crisis [27]. However, the resilient health system sustains a basic level of routine health services and provides additional services for the community [7, 49, 54]. Focus on preventive services before the crisis prepares the health system against shocks, changes, and challenges [7]. In this regard, establishing governance structures, such as safety committees or infection control committees were recommended [49].

\section{Drug and equipment}

Shortages of high-quality drugs and medical equipment are a common problem during the crisis [49]. Using network capacity or collaboration and coordination attributes will improve the efficiency and effectiveness of procurements [27].

\section{Discussion}

General guidance on analysing and implementing health system resilience could be useful to decide how to practice in different contextual situations [7]. However, there is a need to promote resiliency from descriptive or subjective approaches toward an integrated theoretical approach. Thus, this study aimed to achieve a comprehensive model to analyse and guide achieving health system resiliency [11]. For this purpose, a critical interpretive synthesis was applied.

We include studies from various disciplines to strengthen health system resilience concept. Most of the studies focused on similar concepts in defining a resilient system. The review of published models, frameworks or theories, showed that each focused on one or two detected dimensions of operationalization of resiliency. For example, Kruke et al. [9] Hollnagel et al. [8] and Bruneau et al. [72], focused on resilient system attributes, also Blanche et al. [10] and Barasa et al. [6] focused on resilient system strategies and attributes, and Rogers focused on phases of reaching resiliency [73].

Therefore, we concluded that a combination of different dimensions of resilience models, frameworks, and theories are necessary for its analysis and operationalization. Several studies tried to introduce a comprehensive model. In this regard, Wiig et al., in their study, referred to four dimensions to define and research the resilience concept including the purpose of resiliency, activators, and triggers of resilience, system components, and finally processes, activities and mechanisms to enable system resiliency [53]. Also, Thomas et al. defined resilience by three dimensions of preparation, management (absorptive, adaptive, and transformative strategies), and learning (recovery).

The results of this study indicated five main themes to explain and analyze health system resilience (Fig. 2). The relationship and amount of investment in different dimensions determine based on the type of stressors and underlying conditions [44].

Policymakers and researchers can analyze and formalize their resilient system roadmap considering these dimensions. First, Resilience phases are introduced in order. However, as the system moves toward resilience, these phases will proceed continuously and in relation to each other. Second, considering the importance of the resilience concept as a dynamic health system objective to achieve health system goals [53, 74], resilient system attributes, also named "intermediate objectives" and health system goals are introduced. Third, to determine the boundaries of analysis [20, 25, 44, 45, 48, 71], the WHO health system's six building blocks are considered as a necessary dimension for the analysis. Finally, the resilient system enablers' identification is the prerequisite 


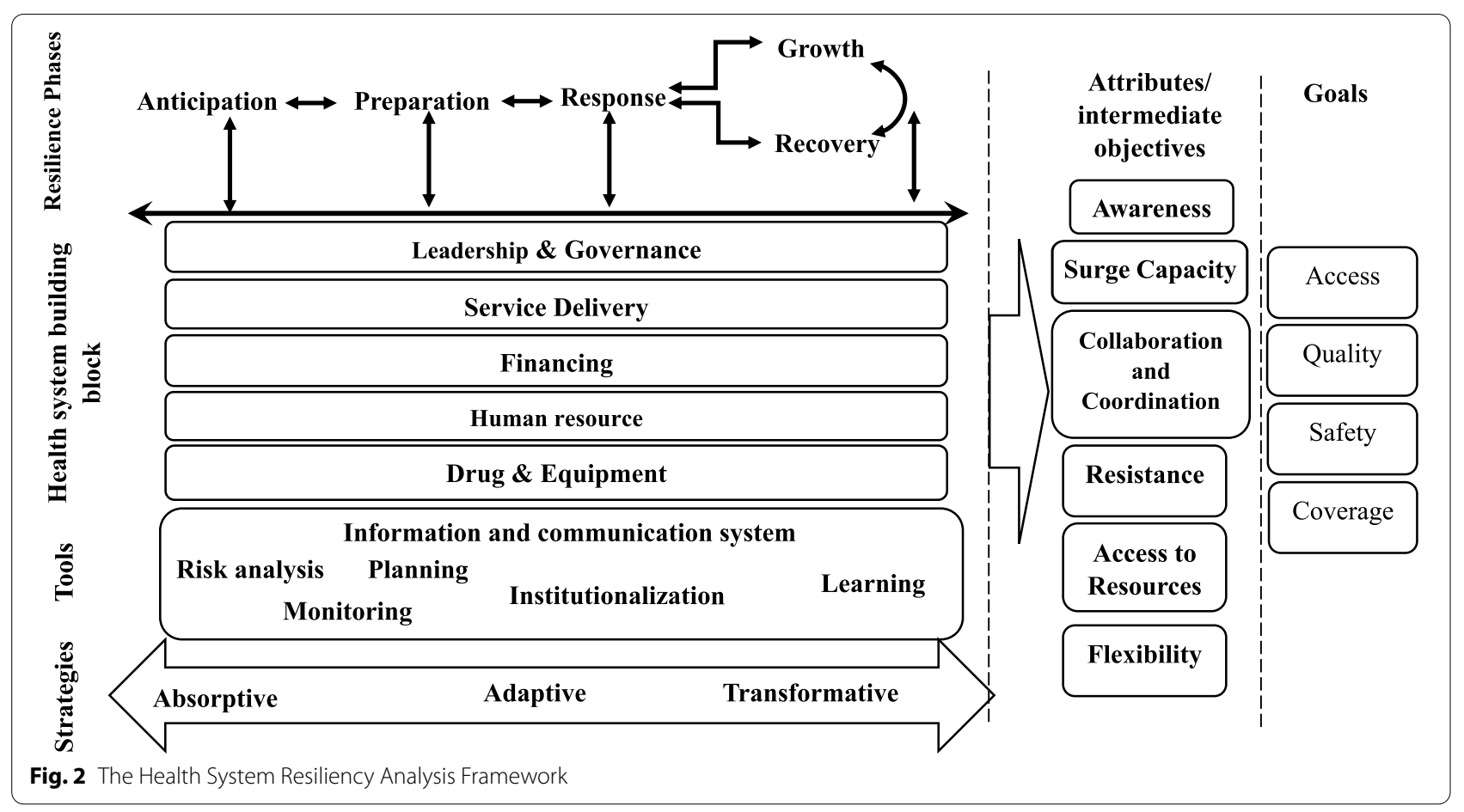

to deeper understanding and analyzing system resilience $[53,75]$. Therefore, in our model, these enablers are introduced as resilience system tools that will be used as an absorptive, adaptive, or transformative strategy.

\section{Conclusion}

This meta-framework provides the opportunity to analyze and identify the strengths and weaknesses of the system in achieving resilience in different contexts. For this purpose, the system's performance will be examined against the crisis in each phase using appropriate indicators. This analysis will be conducted separately in each system building block. Also, applying different resilience tools such as risk analysis, monitoring, information and communication systems, learning, and institutionalization will be assessed. Consequently, the health system will be judged in terms of achieving resilient system attributes and then the health system goals. Finally, related policies in each dimension can be suggested.

\section{Abbreviations}

WHO: World Health Organization; PRISMA: Preferred Reporting Items for Systematic Reviews and Meta-Analyses; COVID-19: Corona Virus Disease of 2019.

\section{Supplementary Information}

The online version contains supplementary material available at https://doi. org/10.1186/s12889-022-12496-3.

Additional file 1. PRISMA 2020 Checklist.

Acknowledgements

The authors would like to acknowledge the support of Iran university of medical sciences.

\section{Authors' contributions}

ZF: Conceptualization, Methodology, Writing - Original Draft PE: Project administration, Supervision, Validation AA: Writing - Review \& Editing MM: Writing - Review \& Editing ShY: Conceptualization, Methodology. All authors read and approved the final manuscript.

\section{Funding}

This study was part of a PhD thesis supported by Iran University of Medical Sciences, Iran (IUMS/SHMIS_1397-3-37-12709).

Availability of data and materials

All data generated or analysed during this study are included in this published article [and its supplementary information files].

\section{Declarations}

Ethics approval and consent to participate Not applicable.

Consent for publication

Not applicable.

Competing interests

The authors declared that they have no competing interests. 


\section{Author details}

${ }^{1}$ School of Health Management and Information Sciences, Iran University of Medical Sciences, Tehran, Iran. ${ }^{2}$ Virtual School of Medical Education and Management, Shahid Beheshti University of Medical Sciences, Tehran, Iran.

Received: 7 June 2021 Accepted: 3 January 2022

Published online: 12 February 2022

\section{References}

1. Kieny MP, Bekedam H, Dovlo D, Fitzgerald J, Habicht J, Harrison G, et al. Strengthening health systems for universal health coverage and sustainable development. Bull World Health Organ. 2017;95(7):537.

2. Turenne CP, Gautier L, Degroote S, Guillard E, Chabrol F, Ridde V. Conceptual analysis of health systems resilience: a scoping review. Soc Sci Med. 2019:232:168-80.

3. Haldane V, Ong S-E, Chuah FL-H, Legido-Quigley H. Health systems resilience: meaningful construct or catchphrase? Lancet. 2017;389(10078):1513.

4. Tumusiime $P$, Nabyonga-Orem J, Karamagi $H$, Lehmann U, Elongo T, Nikiema J-B, et al. Resilient health systems for attaining universal health coverage. BMJ Spec J. 2019:4(9):e002006.

5. Thomas S, Sagan A, Larkin J, Cylus J, Figueras J, Karanikolos M. Strengthening health systems resilience: key concepts and strategies; 2020.

6. Barasa E, Mbau R, Gilson L. What is resilience and how can it be nurtured? A systematic review of empirical literature on organizational resilience. Int J Health Policy Manag. 2018;7(6):491.

7. Fridell M, Edwin S, Von Schreeb J, Saulnier DD. Health system resilience: what are we talking about? A scoping review mapping characteristics and keywords. Int J Health Policy Manag. 2020;9(1):6.

8. Hollnagel E, Woods DD, Leveson N. Resilience engineering: concepts and precepts. England: Ashgate Publishing, Ltd.; 2006.

9. Kruk ME, Ling EJ, Bitton A, Cammett M, Cavanaugh K, Chopra M, et al. Building resilient health systems: a proposal for a resilience index. BMJ. 2017;357:j2323.

10. Blanchet K, Nam SL, Ramalingam B, Pozo-Martin F. Governance and capacity to manage resilience of health systems: towards a new conceptual framework. Int J Health Policy Manag. 2017;6(8):431.

11. Berg SH, Akerjordet K, Ekstedt M, Aase K. Methodological strategies in resilient health care studies: an integrative review. Saf Sci. 2018;110:300-12.

12. Biddle L, Wahedi K, Bozorgmehr K. Health system resilience: a literature review of empirical research. Health Policy Plan. 2020;35(8):1084-109.

13. Hong QN, Fàbregues S, Bartlett G, Boardman F, Cargo M, Dagenais P, et al. The mixed methods appraisal tool (MMAT) version 2018 for information professionals and researchers. Educ Inf. 2018;34(4):285-91.

14. Falegnami A, Bilotta F, Pugliese F, Costantino F, Di Gravio G, Tronci M, et al. A multicountry comparative survey about organizational resilience in anaesthesia. J Eval Clin Pract. 2018;24(6):1347-57.

15. Dixon-Woods M, Cavers D, Agarwal S, Annandale E, Arthur A, Harvey $J$, et al. Conducting a critical interpretive synthesis of the literature on access to healthcare by vulnerable groups. BMC Med Res Methodol. 2006:6(1):1-13.

16. Ako-Arrey DE, Brouwers MC, Lavis JN, Giacomini MK. Health systems guidance appraisal — a critical interpretive synthesis. Implement Sci. 2015;11(1):1-20

17. Egger M, Smith GD, Phillips AN. Meta-analysis: principles and procedures. BMJ. 1997:315(7121):1533-7.

18. Dixon-Woods M, Bonas S, Booth A, Jones DR, Miller T, Sutton AJ, et al. How can systematic reviews incorporate qualitative research? A critical perspective. Qual Res. 2006;6(1):27-44

19. Keliddar I, Mosadeghrad AM, Jafari-Sirizi M. Rationing in health systems: a critical review. Med J Islam Repub Iran. 2017;31:47.

20. Meyer D, Bishai D, Ravi SJ, Rashid H, Mahmood SS, Toner E, et al. A checklist to improve health system resilience to infectious disease outbreaks and natural hazards. BMJ Glob Health. 2020;5(8):e002429.

21. de Carvalho PVR, de Souza AP, Gomes JO. A computerized system to monitor resilience indicators in organizations. Work. 2012;41(Supplement 1):2803-9.
22. Thomas S, Keegan C, Barry S, Layte R, Jowett M, Normand C. A framework for assessing health system resilience in an economic crisis: Ireland as a test case. BMC Health Serv Res. 2013:13(1):1-8.

23. Shirali GA, Azadian S, Saki A. A new framework for assessing hospital crisis management based on resilience engineering approach. Work. 2016;54(2):435-44.

24. Haghighi SM, Torabi SA. A novel mixed sustainability-resilience framework for evaluating hospital information systems. Int J Med Inform. 2018;118:16-28.

25. Patriarca R, Di Gravio G, Costantino F, Falegnami A, Bilotta F. An analytic framework to assess organizational resilience. Saf Health Work. 2018;9(3):265-76

26. Ho K, Al-Shorjabji N, Brown E, Zelmer J, Gabor N, Maeder A, et al. Applying the resilient health system framework for universal health coverage. Stud Health Technol Inform. 2016;231:54-62.

27. Therrien M-C, Normandin J-M, Denis J-L. Bridging complexity theory and resilience to develop surge capacity in health systems. J Health Organ Manag. 2017:31(1):96-109.

28. Barker KM, Ling EJ, Fallah M, VanDeBogert B, Kodl Y, Macauley RJ, et al. Community engagement for health system resilience: evidence from Liberia's Ebola epidemic. Health Policy Plan. 2020;35(4):416-23.

29. Anderson J, Ross A, Back J, Duncan M, Snell P, Walsh K, et al. Implementing resilience engineering for healthcare quality improvement using the CARE model: a feasibility study protocol. Pilot Feasibility Stud. 2016:2(1):1-9.

30. Najarian M, Lim GJ. Design and assessment methodology for system resilience metrics. Risk Anal. 2019:39(9):1885-98.

31. Omidvar M, Mazloumi A, Mohammad Fam I, Nirumand F. Development of a framework for resilience measurement: suggestion of fuzzy resilience grade (RG) and fuzzy resilience early warning grade (REWG). Work. 2017:56(3):463-74

32. Barasa EW, Cloete K, Gilson L. From bouncing back, to nurturing emergence: reframing the concept of resilience in health systems strengthening. Health Policy Plan. 2017;32(suppl_3):iii91-i4.

33. Cristian B. Hospital resilience: a recent concept in disaster preparedness. J Crit Care Med. 2018:4(3):81-2.

34. Ybarra N. Hurricane Harvey: one hospital's journey toward organizational resilience. J Perinat Neonatal Nurs. 2019;33(3):246-52.

35. Gilson L, Barasa E, Nxumalo N, Cleary S, Goudge J, Molyneux S, et al. Everyday resilience in district health systems: emerging insights from the front lines in Kenya and South Africa. BMJ Glob Health. 2017;2(2):e000224.

36. Frisbie K, Converso J. Organizational resilience and enrollment trends of independent, for-profit higher education institutions. Work. 2016;54(2):295-308.

37. Moran KA. Organizational resilience: sustained institutional effectiveness among smaller, private, non-profit US higher education institutions experiencing organizational decline. Work. 2016:54(2):267-81.

38. Witmer $\mathrm{H}$, Mellinger MS. Organizational resilience: nonprofit organizations' response to change. Work. 2016;54(2):255-65.

39. Rangachari $P$, Woods JL. Preserving organizational resilience, patient safety, and staff retention during COVID-19 requires a holistic consideration of the psychological safety of healthcare workers. Int J Environ Res Public Health. 2020:17(12):4267.

40. Kong J, Simonovic SP. Probabilistic multiple hazard resilience model of an interdependent infrastructure system. Risk Anal. 2019;39(8):1843-63.

41. Khan Y, O'Sullivan T, Brown A, Tracey S, Gibson J, Généreux M, et al. Public health emergency preparedness: a framework to promote resilience. BMC Public Health. 2018;18(1):1-16.

42. Argyroudis SA, Mitoulis SA, Hofer L, Zanini MA, Tubaldi E, Frangopol DM Resilience assessment framework for critical infrastructure in a multihazard environment: case study on transport assets. Sci Total Environ. 2020;714:136854

43. Clay-Williams R, Braithwaite J. Resilient health care: a determinant framework for understanding variation in everyday work and designing sustainable digital health systems. Stud Health Technol Inform. 2019:263:134-45.

44. Kagwanja N, Waithaka D, Nzinga J, Tsofa B, Boga M, Leli H, et al. Shocks, stress and everyday health system resilience: experiences from the Kenyan coast. Health Policy Plan. 2020;35(5):522-35.

45. Pęciłło $\mathrm{M}$. The concept of resilience in $\mathrm{OSH}$ management: a review of approaches. Int J Occup Saf Ergon. 2016;22(2):291-300. 
46. Vos J, Franklin B, Chumbley G, Galal-Edeen G, Furniss D, Blandford A. Nurses as a source of system-level resilience: secondary analysis of qualitative data from a study of intravenous infusion safety in English hospitals. Int J Nurs Stud. 2020;102:103468.

47. Rios C, Ling E, Gutierrez RR, Gonzalez J, Bruce J, Barry M, et al. Puerto Rico health system resilience after hurricane Maria: implications for disaster preparedness in the CoViD-19 era. medRxiv. 2020. https://doi.org/10. 1101/2020.09.20.20198531.

48. Dos Santos VM, de Carvalho RJM, de Carvalho PVR. Roadmap for the development of a resilience indicator system for protection and civil defense organizations: a literature review of the evidence. Work. 2020;66(3):587-601. https://doi.org/10.3233/WOR-203201.

49. Fallah-Aliabadi S, Ostadtaghizadeh A, Ardalan A, Fatemi F, Khazai B, Mirjalili MR. Towards developing a model for the evaluation of hospital disaster resilience: a systematic review. BMC Health Serv Res. 2020;20(1):64.

50. Woods DD, Chan YJ, Wreathall J, editors. The stress-strain model of resilience operationalizes the four cornerstones of resilience engineering. France: 5th Resilience Engineering Symposium; 2014

51. Specking E, Cottam B, Parnell G, Pohl E, Cilli M, Buchanan R, et al. Assessing engineering resilience for systems with multiple performance measures. Risk Anal. 2019;39(9):1899-912.

52. Tumusiime $P$, Karamagi $H$, Titi-Ofei $R$, Amri M, Seydi ABW, Kipruto $H$, et al., editors. Building health system resilience in the context of primary health care revitalization for attainment of UHC: proceedings from the Fifth Health Sector Directors' Policy and Planning Meeting for the WHO African Region. BMC proceedings; 2020;14(19):16. https://doi.org/10.1186/ s12919-020-00203-2.

53. Wiig S, Aase K, Billett S, Canfield C, Røise O, Njå O, et al. Defining the boundaries and operational concepts of resilience in the resilience in healthcare research program. BMC Health Serv Res. 2020;20:1-9.

54. Nuzzo JB, Meyer D, Snyder M, Ravi SJ, Lapascu A, Souleles J, et al. What makes health systems resilient against infectious disease outbreaks and natural hazards? Results from a scoping review. BMC Public Health. 2019;19(1):1-9.

55. Iflaifel M, Lim RH, Ryan K, Crowley C. Resilient health care: a systematic review of conceptualisations, study methods and factors that develop resilience. BMC Health Serv Res. 2020;20:1-21.

56. OECD. Guidelines for resilience systems analysis. 2014.

57. Li PP. Organizational resilience for a new normal: balancing the paradox of global interdependence. Manag Organ Rev. 2020;16(3):503-9.

58. Rai SS, Rai S, Singh NK. Organizational resilience and social-economic sustainability: COVID-19 perspective. Environ Dev Sustain. 2021;23:12006-23. https://doi.org/10.1007/s10668-020-01154-6.

59. Hillmann J, Guenther E. Organizational resilience: a valuable construct for management research? Int J Manag Rev. 2021;23(1):7-44.

60. Patriarca R, Gravio GD, Costantino F, Tronci M, Severoni A, Vernile A, et al. A paradigm shift to enhance patient safety in healthcare, a resilience engineering approach: scoping review of available evidence. Int J Healthc Technol Manag. 2017;16(3-4):319-43.

61. Annarelli A, Battistella C, Nonino F. A framework to evaluate the effects of organizational resilience on service quality. Sustainability. 2020;12(3):958.

62. Anderson J, Ross A, Macrae C, Wiig S. Defining adaptive capacity in healthcare: a new framework for researching resilient performance. Appl Ergon. 2020;87:103111.

63. Darkow PM. Beyond "bouncing back": towards an integral, capabilitybased understanding of organizational resilience. J Contingencies Crisis Manag. 2019;27(2):145-56.

64. Ma Z, Xiao L, Yin J. Toward a dynamic model of organizational resilience. Nankai Bus Rev Int. 2018;9(3):246-263.

65. Ruiz-Martin C, López-Paredes A, Wainer G. What we know and do not know about organizational resilience. Int J Prod Manag Eng. 2018;6(1):11-28.

66. Pal R, Torstensson H, Mattila H. Antecedents of organizational resilience in economic crises - an empirical study of Swedish textile and clothing SMEs. Int J Prod Econ. 2014;147:410-28.

67. Liu Y, Yin J. Stakeholder relationships and organizational resilience. Manag Organ Rev. 2020;16(5):986-90.

68. Cotta D, Salvador F. Exploring the antecedents of organizational resilience practices-a transactive memory systems approach. Int J Oper Prod Manag. 2020;40(9):1531-59.
69. Albanese J, Birnbaum M, Cannon C, Cappiello J, Chapman E, Paturas J, et al. Fostering disaster resilient communities across the globe through the incorporation of safe and resilient hospitals for community-integrated disaster responses. Prehosp Disaster Med. 2008;23(5):385-90.

70. Gilson L, Ellokor S, Lehmann U, Brady L. Organizational change and everyday health system resilience: lessons from Cape Town, South Africa. Soc Sci Med. 2020;266:113407.

71. Mfutso-Bengo J, Kalanga N, Mfutso-Bengo EM. Proposing the LEGS framework to complement the WHO building blocks for strengthening health systems: one needs a LEG to run an ethical, resilient system for implementing health rights. Malawi Med J. 2017;29(4):317-21.

72. Bruneau M, Chang SE, Eguchi RT, Lee GC, O'Rourke TD, Reinhorn AM, et al. A framework to quantitatively assess and enhance the seismic resilience of communities. Earthquake Spectra. 2003;19(4):733-52.

73. Rogers P. Development of resilient Australia: enhancing the PPRR approach with anticipation, assessment and registration of risks. Aust J Emerg Manag. 2011;26(1):54-8.

74. Kutzin J, Sparkes SP. Health systems strengthening, universal health coverage, health security and resilience. Bull World Health Organ. 2016;94(1):2.

75. Jeppesen E, Wiig S. Resilience in a prehospital setting-a new focus for future research? Scand J Trauma Resusc Emerg Med. 2020;28(1):1-4.

\section{Publisher's Note}

Springer Nature remains neutral with regard to jurisdictional claims in published maps and institutional affiliations.

Ready to submit your research? Choose BMC and benefit from:

- fast, convenient online submission

- thorough peer review by experienced researchers in your field

- rapid publication on acceptance

- support for research data, including large and complex data types

- gold Open Access which fosters wider collaboration and increased citations

- maximum visibility for your research: over 100M website views per year

At BMC, research is always in progress.

Learn more biomedcentral.com/submissions 